\title{
Processo de Ensino-Aprendizagem de Línguas e Interculturalidade na Formação de Professores Indígenas
}

\author{
Language Teaching-Learning Process and
}

Interculturality in the Training of Indigenous Teachers

Jonise Nunes Santos

Universidade Federal do Amazonas (UFAM) ${ }^{1}$

Resumo. O artigo aborda aspectos teórico-metodológicos no processo de desenvolvimento de disciplinas da área Letras e Artes, da Licenciatura em Formação de Professores Indígenas - FPI/Faculdade de Educação - FACED/Universidade Federal do Amazonas - UFAM. Metodologicamente, utiliza-se da pesquisa documental para apresentar a estrutura da Licenciatura da FACED, da pesquisa bibliográfica para fundamentar os procedimentos metodológicos que conversam com as práticas docentes do Formador, cujo entendimento básico sobre as disciplinas relacionadas ao processo ensino-aprendizado de línguas deve seguir o princípio de que, em contextos plurilíngues e pluriculturais, "não é possível tomar como unidades básicas do processo de ensino os que decorrem de uma análise de estratos, letras/fonemas, sílabas, palavras, sintagmas, frases descontextualizados" (BRASIL, 1996, p. 23). Para tanto, utiliza-se como ponto de partida para atividades das disciplinas o conhecimento prévio dos alunos sobre a ementa, que são somados a textos teóricos, visando cumprir a interculturalidade, por ser um dos objetivos da Licenciatura FPI e um dos objetivos da Educação Escolar Indígena. Amplia-se a discussão na disciplina com adoção de procedimentos metodológicos que possam subsidiar as atividades do acadêmico durante o exercício da docência na escola indígena, assim, apropria-se da reflexões contidas na Pedagogia de Projetos, na Sequência Didática de Ensino, nas propostas de Freinet para o processo pedagógico e na transposição didática. Dessa forma, a oferta das disciplinas caracteriza-se também como momento para que o professor indígena reflita sobre sua prática pedagógica e sobre o atendimento às Diretrizes Curriculares Nacionais para a Educação Escolar Indígena, mediante o planejamento de ações, que o desafia a considerar os conhecimentos dos alunos e do povo nas ações da escola. Essa perspectiva de ensino busca ainda refletir sobre padrões fechados do processo ensinoaprendizagem, utilizados há séculos e só permitem uma interpretação, logo, negam a diversidade de leituras possíveis que se constrói na co-interação leitor-texto e conhecimentos indígenas.

Palavras-chave: Processo ensino-aprendizagem. Formação de Professores Indígenas. Interculturalidade.

Abstract: The article addresses theoretical and methodological aspects in the process of developing disciplines in the area of Letters and Arts, from the Degree in Training of Indigenous Teachers - FPI / Faculty of Education - FACED / Federal University of Amazonas - UFAM. Methodologically, it uses documentary research to present the structure of the FACED Licentiate Degree, bibliographic research to support methodological procedures that talk to the Trainer's teaching practices, whose basic understanding of the disciplines related to the teaching-learning process of languages must follow the principle that, in plurilingual and pluricultural contexts, "it is not possible to take as basic units of the teaching process those that result from an analysis of strata, letters / phonemes, syllables, words, phrases, phrases out of context" (BRASIL, 1996, p. 23). To do so, students' prior knowledge of the menu is used as a starting point for activities in the disciplines, which are added to theoretical texts, aiming at fulfilling interculturality, as it is one of the objectives of the FPI Degree and one of the objectives of School Education Indigenous. The discussion in the discipline is broadened with the adoption of methodological procedures that can subsidize the activities of the academic during the exercise of

\footnotetext{
${ }^{1}$ Doutoranda do Programa de Pós-Graduação em Letras da Universidade Federal do Pará (PPGL/UFPA).
} 
teaching in the indigenous school, thus, it appropriates the reflections contained in the Project Pedagogy, in the Didactic Sequence of Teaching, in the proposals of Freinet for the pedagogical process and didactic transposition. Thus, the offer of disciplines is also characterized as a time for the indigenous teacher to reflect on his pedagogical practice and on the fulfillment of the National Curriculum Guidelines for Indigenous School Education, through the planning of actions, which challenges him to consider the knowledge students and the people in the school's actions. This teaching perspective also seeks to reflect on closed patterns of the teaching-learning process, used for centuries and only allow an interpretation, therefore, they deny the diversity of possible readings that is built in the reader-text co-interaction and indigenous knowledge.

Keywords: Teaching-learning process. Training of Indigenous Teachers. Interculturality.

\section{Introdução}

O processo educacional destinado aos povos indígenas, nas últimas décadas, vem buscando construir uma Educação Escolar Indígena pautada nos princípios do comunitarismo, diferenciação, especificidade, bi/multilinguismo e interculturalidade. Nessa mesma perspectiva, conceitos como cultura, alteridade, diferença, identidade, memória e direitos indígenas vêm sendo retomados para compreensão e interpretação do contexto, em função da contradição entre a legislação e a prática pedagógica na escola indígena.

Esse olhar contraditório pode ser observado desde o período da colonização brasileira. Xavier, Ribeiro e Noronha (1994, p. 42) informam que os dados históricos, referentes ao ensino destinado aos povos indígenas no processo de colonização, demonstram a utilização de "métodos autoritários e controladores com o propósito de dominar os povos indígenas, considerados selvagens e ingênuos, com a finalidade de integrá-los à civilização, a serviço da fé e do império".

A prática de ensino jesuítica utilizava ações e métodos que alteravam os valores indígenas, considerando que "não aprendiam apenas uma nova língua, uma nova interpretação da vida e da morte", pelo contrário, a didática possibilitava "um renascer que alterava pela base a vida cotidiana daquela população nativa e a sua própria compreensão do significado da existência" (XAVIER; RIBEIRO; NORONHA, 1994, p.42).

O processo pedagógico oferecido aos indígenas se valia de conteúdos e métodos que atendiam apenas às classes dominantes, logo não atendiam às peculiaridades das centenas de povos. Ressalta-se que essa prática atravessou séculos e ainda é presente nas escolas indígenas, apesar de já ser garantido em legislação específica o direito a uma escola que atenda aos projetos societários de cada aldeia.

Dentre os direitos específicos, destaca-se a Formação Específica de Professores Indígenas, considerando que a escola indígena deve ser conduzida, segundo a Resolução CNE/CEB N. 05/2012, por professores indígenas, como docentes e como gestores, pertencentes às suas respectivas comunidades, mas, para isso, precisa-se que tenham formação fundamentada nas demandas reais da aldeia e dos acadêmicos.

A Resolução CNE/CEB N. 05/2012 destaca que os cursos de formação de professores indígenas, em nível médio ou superior, devem enfatizar a constituição de competências referenciadas em conhecimentos, saberes e valores, pautados nos princípios da Educação Escolar 
Indígena; assim como devem estar voltados ao desenvolvimento e à avaliação de currículos e programas próprios, bem como à produção de materiais didáticos e à utilização ensino e pesquisa na escola (BRASIL, 2012). Assim, é prioridade formação que dê subsídios teóricos e práticos aos professores indígenas, que na Faculdade de Educação (FACED), da Universidade Federal do Amazonas (UFAM), vem sendo realizada pelo Curso de Licenciatura em Formação de Professores Indígenas (FPI), visando suprir a formação de profissionais da Educação Básica das escolas indígenas.

A Licenciatura em FPI, com apoio técnico e financeiro do Ministério da Educação (MEC), por meio do Programa de Licenciaturas Interculturais Indígenas (PROLIND), na primeira turma, atendeu professores exclusivamente do Povo Mura e foi finalizada em novembro de 2013. As duas turmas seguintes formaram professores dos povos Munduruku e Sateré-Mawé, em 2018. Atualmente, o curso conta com 05 turmas: Médio Solimões, Alto Rio Negro, Alto Solimões, Manicoré e Lábrea, organizadas por Território Etno-Educacional, isto é, são turmas multiétnicas e multilíngues, em conformidade ao Decreto no 6.861, de 27 de maio de 2009.

O Curso FPI objetiva formar, em nível superior, nas áreas Ciências Humanas e Sociais, Ciências Exatas e Biológicas e Letras e Artes, em perspectiva intercultural e interdisciplinar, professores indígenas para atuar nos anos finais do Ensino Fundamental e no Ensino Médio, nas escolas indígenas. Os objetivos específicos do curso se voltam, dentre outros, a "oferecer condições para que as escolas indígenas possam promover o acesso aos saberes científicos historicamente construídos pela humanidade, bem como a valorização do patrimônio indígena, propiciando um diálogo intercultural, a partir de suas lógicas e valores" (UFAM-FACED, 2010).

Conforme Santos e Santos (2014, p. 2.875), a duração do curso é de cinco anos. Nesse período, em dois anos, ocorre a formação geral, para estudo de fundamentos pedagógicos e de noções básicas introdutórias às três grandes áreas. Nessa etapa, todos os alunos indígenas estudam juntos. Posteriormente, inicia-se a formação específica, quando os alunos se dividem em três turmas, destinadas ao aprofundamento em uma das áreas: Ciências Humanas e Sociais - História, Geografia, Antropologia, Sociologia e Filosofia; Ciências Exatas e Biológicas - Matemática, Química, Física e Biologia; e Letras e Artes - Língua Portuguesa, Língua Indígena, Expressão Cultural e Práticas Corporais. Na última etapa, ocorre a integração das áreas, quando os alunos voltam a formar uma única turma para discutirem os resultados das pesquisas, do estágio e outras questões que surgiram ao longo do Curso e na etapa anterior.

Santos e Santos (2014, p. 2.875) destacam que o Curso FPI é resposta institucional da UFAM "às demandas dos movimentos indígenas por formação específica de professores indígenas para atuarem nas escolas das aldeias", materializado em um processo de protagonismo compartilhado, "tendo como sujeitos os professores e lideranças indígenas, representados por suas organizações, e os professores da UFAM/FACED".

No que se refere ao êxito na formação, perpassa, em parte, pela didática dos formadores do curso, que deve ser objeto de reflexão para contribuir com a ressignificação da ação docente dos professores indígenas nas escolas das aldeias e para desvelar outras demandas específicas, que, na Área Letras e Artes, sinalizam, principalmente, para os processos específicos de leituras e escritas, por ainda não atender às demandas indígenas, diante dos desafios linguísticos e culturais próprios da diversidade étnica do estado do Amazonas. 


\section{A Área Letras e Artes da Licenciatura Formação de Professores Indígenas: Contextualizando}

A Licenciatura em Formação de Professores Indígenas volta-se à formação de docentes para os Anos Finais do Ensino Fundamental e do Ensino Médio com carga horária de 3.160 horas, divididas em: I. Formação Geral - 1320 h; II. Formação específica - 840 h; III. Formação para integração das áreas 600 h; Práticas como Componente Curricular - 400h; Outras Formas de Atividades AcadêmicoCientífico-Culturais - 200h e IV. Estágio - 400h.

Da Área Letras e Artes, na Formação Geral, referente à língua oferta-se: Língua Portuguesa I - carga horária de 60 horas e ementário voltado a refletir sobre língua e linguagem, a diversidade linguística, língua oral e língua escrita, aspectos do Português falado pelos indígenas, o conceito de gênero, gêneros orais, gêneros escritos, gêneros textuais na Internet; e Língua Portuguesa II, também com carga horária de 60 horas, cuja ementa propõe discutir noções linguísticas sobre o ensino de língua: o oral e o escrito, conceitos de gramática, aspectos gramaticais da língua padrão, aspectos estruturais do texto escrito, um gênero literário: mitos/lendas, conversão do oral no escrito. Línguas Indígenas na Amazônia, 60 horas, propõe lançar um olhar sobre a panorâmica sincrônico-diacrônica da distribuição das línguas indígenas na Amazônia com enfoque na Língua indígena da Turma e Introdução à Língua Indígena, carga horária de 60 horas e ementa propondo a ampliação do conhecimento da História da língua indígena da Turma: origens, mudanças e interferências. A Matriz curricular registra ainda a disciplina Expressão Cultural I, que em 60 horas se propõe a trabalhar a potência sinestésica da expressão cultural: a percepção sensorial, a expressão individual e grupal nas diversas linguagens que ocasionalmente sejam priorizadas e na intertextualidade que a cultura coloca. Expressão Cultural, criatividade e criticidade.

$\mathrm{Na}$ Formação Específica da Área Letras e Artes, há mais 04 (quatro) níveis de disciplinas, de 60 horas/aulas, voltadas à reflexão sobre a Língua Portuguesa, abrangendo nas respectivas ementas o estudo da Fonética e Fonologia, Morfologia, Sintaxe e História social e linguística do Português. A transplantação do Português para o Brasil. Mudanças históricas de natureza fonético-fonológica, morfossintática e semântica no sistema linguístico do Português. Características sociais e linguísticas do Português no Amazonas. No que se refere ao estudo da Língua Indígena, são ofertadas 04 (quatro) disciplinas, com carga horária de 60 horas, visando construir conhecimentos sobre a Fonética e Fonologia: definições. Processos e regras fonológicas da língua indígena da Turma; Morfologia com enfoque no sistema verbal da língua indígena da turma; A sintaxe e o sintagma na língua indígena da turma; Literatura oral, Controvérsias sobre literatura oral. Gêneros orais na cultura cabocla e indígena da Amazônia: mitos, cantos, lendas, provérbios, adivinhações, formas rituais, canções, discursos habituais, etc. A narratologia.

Para além das disciplinas específicas do estudo das línguas portuguesa e indígena, registrase a disciplina Línguas em Contato: Português e Língua Indígena, 60 horas, cuja ementa contempla a discussão: Línguas em contato. Superestrato, adstrato e substrato. Relações de contato entre a língua indígena e o Português: interferências mútuas possíveis (no léxico, na morfologia, na sintaxe, etc.); mais 02 (duas) disciplinas referentes à Arte: Expressão Cultural II, 60 horas/aula, e ementa voltada aos aspectos diversos da expressão cultural de outros grupos sociais, relacionamento crítico com outras formas de Expressão Cultural dos povos latino-americanos e, particularmente, da Amazônia; e Expressão Cultural III, com carga horária também de 60 horas e ementa propondo a 
releitura e reconstrução de cosmos estéticos diversos, dada a necessidade da relação com a cultura dos povos indígenas. Recriação da chamada Arte Universal, no sentido sinestésico/crítico.

Ainda na Formação Específica na Área Letras e Artes, há a disciplina voltada à formação da Educação Física: Práticas Corporais, com carga horária de 60 horas e ementa contemplando a problematização da historicidade dos povos indígenas através das suas práticas corporais cotidianas do andar, correr, saltar, transportar, lançar, nadar, mergulhar, caçar e outras com características lúdicas, possibilitando a continuidade de suas expressões culturais através da valorização de seus rituais, da transmissão de valores e costumes para as novas gerações.

Registra-se ainda componentes curriculares voltados à Pesquisa em Letras e Artes e Cotidiano do Professor Indígena I e II, ambas com carga horária de 60 horas, objetivando realizar levantamento sociolinguístico, mapeamento dos falantes por idade (entre outras variáveis), língua indígena: número, localização e competência dos falantes que vivem na área, pesquisa lexical: estudo de campos semânticos relacionados à agricultura e à pesca. Elaboração de um glossário comentado, a partir da pesquisa e das análises feitas.

Para organizar as pesquisas realizadas, a Matriz Curricular reserva a disciplina Oficina III Sistematização Final e Apresentação das Pesquisas da Grande Área de Letras e Artes, 60 horas/aula, cuja ementa prevê: sistematização final e elaboração de relatórios e produções diversas ligadas às pesquisas na grande área de Letras e Artes. Apresentação dos resultados das pesquisas. Nessa mesma linha, há a disciplina Estágio II, 135 horas/aula, destinada a elaboração, desenvolvimento e socialização de projetos e relatórios escolares de ensino-pesquisa, relacionados às áreas específicas de formação/atuação dos licenciandos.

Na última etapa do Curso, Formação para Integração das Áreas, há a oferta da disciplina Libras, 60 horas/aula, na qual se aborda a História da Educação de Surdos; políticas educativas para surdos; legislação e surdez; Abordagens educacionais na educação de surdos; Congresso de Milão; Aspectos Morfológicos, Fonológicos, Sintáticos, Semânticos e Pragmáticos da Libras; Análise Contrastiva: Língua Portuguesa e Língua de Sinais; Linguística aplicada à educação de surdos; Parâmetros da Libras; sistema de transcrição, tipos de frases em Libras; incorporação de negação; os classificadores da Libras; expressões facial e corporal; alfabeto manual; datilologia; cultura e identidades surdas; comunidade surda; o movimento surdo no Brasil.

As disciplinas e ementas da Área Letras e Artes da Licenciatura FPI ainda são da Turma ofertada ao povo Mura, monolíngue em língua portuguesa e motivada a vitalizar o Nheengatu, considerando que ainda há falantes nas aldeias. Porém, a proposta curricular não conversa com o objetivo dos acadêmicos, que demandam processos específicos de ensino-aprendizado de outra língua. Para além da especificidade linguística, ainda há o fato de que, enquanto instrumento de resistência identitária, o ensino de língua indígena não deveria ser restrito aos acadêmicos da Área Letras e Artes, já que o cuidado com a língua é responsabilidade do povo, logo deveria envolver todos os acadêmicos da turma.

Posteriormente, em 2011, ingressaram alunos dos povos Munduruku e Sateré-Mawé, em turmas distintas, com perfil sociolinguístico diferente ao da Turma Mura, no entanto, não houve uma reflexão sobre as disciplinas ofertadas na Área Letras e Artes. Essa situação se agrava quando 
se adota, a partir de 2013, a Política de Territórios Etno-Educacionais (TEE) para oferta de novas turmas, independente, da situação sociolinguística do povo.

Nessa configuração, atualmente, o curso de licenciatura em Formação de Professores Indígenas possui a Turma Médio Solimões, que atende professores de 07 (sete) povos diferentes; Turma Alto Solimões - 02 (dois) povos distintos e em extrema relação de contato com os países da fronteira (Peru e Colômbia, logo a presença da língua espanhola, além do português); Turma Alto Rio Negro - 12 (doze) povos; Turma Purus-Lábrea - 05 (cinco) povos e Turma Madeira Manicoré 05 (cinco) povos.

Diante dos objetivos propostos no Projeto Político do Curso (PPC) e da demanda por formação específica de professores indígenas, a Área Letras e Artes é desafiada a formar professores que chegam ao Curso com limitação na formação da educação básica, "seguidores" de uma prática docente baseada no modelo de colonização e integração nacional, e, principalmente, que não "consideram" a diversidade linguística amazônica, que registra mais de 50 línguas com diferente situações de estudo. Há línguas que vêm sendo pesquisadas e sobre a qual se sabe o suficiente para contribuir com o processo educacional do povo; no entanto, há línguas que apresentam pouco ou nenhum estudo, inclusive sem descrição. Em muitos espaços amazônicos, convivem mais de um povo, que falam diferentes línguas de distintas famílias.

A formação na Educação Básica e a prática docente dos acadêmicos ingressos do curso apresentam-se como desafio para a Área Letras e Artes, diante da limitação que a maioria dos acadêmicos demonstra com relação à leitura e à escrita, incluindo letramento e alfabetização. Os alunos sempre são de um contexto que não há energia elétrica, nem livros. Além de professoresdiscentes, também são agricultores, pescadores, caçadores. São oriundos de classes multisseriadas, do Magistério Indígena, ou do Ensino Médio mediado por Tecnologia, que não considera a especificidade linguística dos alunos.

Acrescenta-se a isso, a ausência de formação continuada e orientação pedagógica diferenciada e específica aos indígenas que assumem a docência nas aldeias sem formação, devido à necessidade das aldeias, adotando como prática pedagógica a reprodução de modelos de ensino pautados na supressão das línguas indígenas, ou seja, o exercício docente baseado no modelo dos seus antigos professores, que não priorizaram e nem consideraram oralidade, conhecimento tradicional dos povos, produção textual, leitura e releitura.

Diante desse contexto, como formar professores que devem contribuir para o projeto societário de seu respectivo povo, especificamente para atuarem no ensino de línguas, artes e práticas corporais e que ainda devem intervir na violenta relação de contato que os povos indígenas são submetidos, atingindo diretamente a autoestima de cada aluno-professor, que teme ousar em adotar outra forma de ser professor?

Sabe-se que o processo de ensino-aprendizagem em qualquer contexto de Educação Escolar Indígena perpassa pela sistematização de conhecimentos, por meio de pesquisas, leituras, experimentações, no entanto, como realizar, a contento, essas ações? Como fazer pesquisa? Entende-se que para conseguir minimizar os desafios, o elemento relevante é adotar metodologia que os alunos-professores sejam os pesquisadores de suas realidades juntamente com seus alunos e comunidade da escola da aldeia. 
Por meio da pesquisa, partindo da observação, do registro da prática docente de cada alunoprofessor, e os direcionando à reflexão e a outras experiências docentes de ensino-aprendizagem supõe-se que é possível contribuir com a ressignificação dos modelos utilizados no processo de ensino de línguas, que não tem contribuído para a construção da autonomia indígena, nem para construir uma escola indígena que atenda aos princípios da educação diferenciada: Comunitária, Intercultural, Específica, Diferenciada, Bi/Multilíngue.

Nesse sentido, a inserção de discussões sobre procedimentos metodológicos na Área Letras e Artes da Licenciatura FPI/FACED/UFAM visa contribuir com a diminuição da distância entre as epistemologias ocidentais e as indígenas, para ser apontado o que é relevante aos povos indígenas nesse processo de formação linguística dos seus docentes, que no Amazonas apresenta-se variadas situações, conforme a relação de contato estabelecida com a sociedade envolvente.

\section{Processo Ensino-aprendizagem de Línguas, Interculturalidade e Formação de Professores Indígenas}

O Curso de Licenciatura da FACED, destinado aos povos indígenas, adota a modalidade de ensino/formação por módulos e oficinas pedagógicas, para subsidiar os currículos escolares, possibilitar a melhoria do trabalho pedagógico nas escolas indígenas e equacionar as problemáticas vivenciadas nas aldeias e comunidades. Nesse contexto, a ação do docente-formador do curso deve se pautar no cumprimento da ementa, observando o processo educacional na aldeia, em uma perspectiva de ensino intercultural, desafiador de preconceitos e valorizador dos conhecimentos próprios de cada povo.

Para tanto, faz-se necessário ressignificação de procedimentos metodológicos e pesquisa em escolas indígenas, fundamentado no desenvolvimento de um "percurso" de ensino-aprendizagem, que se inicia com diagnóstico da realidade e conhecimento prévio do cursista; seguido de aprofundamento teórico-conceitual da disciplina, realização de exercícios, por meio da materialização do que foi apreendido até a transposição didática dos conteúdos acadêmicos para a escola indígena.

Esse processo visa envolver o contexto linguístico da turma, o cumprimento das orientações nacionais específicas para Educação Escolar Indígena, os objetivos e ementários, na carga horária disponível para realização de 01 (uma) disciplina (60 horas, em 7,5 dias), que provocam a experimentação de uma prática docente que responda às demandas apresentadas no decorrer da formação.

Partindo de observações, realização de oficinas, leituras, dos conhecimentos prévios e reflexões dos alunos e dos saberes próprios de cada povo, foi-se ressignificando ao longo da atuação docente no Curso FPI, proposta para contribuir com o processo de ensino-aprendizagem na formação dos professores indígenas, na qual sejam respeitados os princípios básicos da escola indígena. Assim, optou-se primeiramente pela Pedagogia de Projetos, que foi complementada pelas ideias de Freinet, pela Sequência Didática de Ensino de Línguas e pela Transposição Didática.

Similar ao que se propõe para a escola indígena, John Dewey $(1979$, p.16) afirma que a escola deve estar conectada com a vida social em geral, com o trabalho de todas as demais instituições que envolvem o contexto do aluno, pois a educação é um processo de vida e não uma preparação 
para a vida futura, logo a escola deve representar a vida presente tão real e vital para o aluno como ele vive no cotidiano.

Essa concepção se materializa na Pedagogia de Projetos, que tende a ressignificar a escola e colaborar na ressignificação no ensino e na formação. O método por projetos objetiva que os saberes escolares sejam integrados com os saberes sociais, possibilitando um processo intercultural, quando o aluno estiver aprendendo, por meio de elementos da vida pessoal, sobre outros conhecimentos de outras sociedades. Hernandez (1998, p. 61) destaca que trabalhar com projetos aproxima a "identidade dos alunos e favorece a construção da subjetividade, longe de um prisma paternalista, gerencial ou psicologista, o que implica considerar que a função da escola não é apenas ensinar conteúdos, nem vincular a instrução com a aprendizagem".

No que se refere ao trabalho docente, a Pedagogia de Projetos possibilita a revisão da "organização do currículo por disciplinas" e sua localização "no tempo e no espaço escolar", desencadeando na "proposta de um currículo que não fragmenta" o conhecimento, distante "dos problemas que os alunos vivem e necessitam responder em suas vidas, mas, sim, solução de continuidade" (HERNANDEZ, 1998, p.61).

Nesse sentido, na formação dos professores indígenas, orienta-se a realização do processo educacional tendo por base a Pedagogia de Projetos, partindo de um tema gerador sobre a cultura do povo, para então serem abordados outros temas referentes ao conteúdo e as atividades para serem desenvolvidos com turmas multisseriadas. Ressalta-se que os temas escolhidos se referem sempre aos conhecimentos tradicionais indígenas que estão deixando de ser considerados na aldeia.

Essa prática oportuniza, ainda, que se considere o que acontece "fora da escola, a produção de informação da sociedade, para dialogar com todos esses fenômenos", rompendo "com as limitações do cotidiano, com a postura do professor tradicional", possibilitando a circulação de informações na escola em "referência à realidade do educando", valorizando "os temas geradores e não mais seguir à risca os livros didáticos, alunos parados, dentre outros fatores que contribuem para a inovação educacional" (HERNANDEZ, 1998, p. 61).

A inserção da Pedagogia de Projetos no contexto da escola indígena deve-se ao fato de que esse método supõe um "enfoque do ensino que ressitua a concepção e as práticas educativas na escola, para dar resposta às mudanças sociais, que se produz" na educação, envolvendo "as questões reais para favorecer o desenvolvimento do aluno" (HERNANDEZ, 1998, p.61). Nesse sentido, a pedagogia de projetos na escola indígena visa à ressignificação do espaço escolar em um ambiente de interações, tendo o professor como mediador do processo de construção do trabalho, baseado em atividade de pesquisa, por meio da qual tanto o professor quanto o aluno tendem a descobrir coisas novas. É possível ainda fortalecer ou revitalizar conhecimentos que estão sendo suprimidos pela relação de contato entre os povos indígenas e outras culturas.

A utilização do conhecimento prévio que o aluno traz de casa ajuda na participação e na valorização dos pais, que pensam não ter conhecimentos para ajudar os filhos na escola, além de contribuir para a participação da comunidade, na troca de conhecimento, transformando-se em um círculo contínuo e produtivo à educação e ao desenvolvimento da aprendizagem. Na formação de 
professores indígenas permite que o aluno possa vivenciar os conhecimentos de seu povo ao mesmo tempo em que se abre a múltiplas relações com outros conhecimentos.

Ao desenvolvimento do projeto para serem realizados pelos professores indígenas em formação em suas escolas, acrescenta-se as contribuições significativas de Freinet $(1969,1973$, 1979) para repensar as práticas pedagógicas, o papel do professor e do próprio aluno, conduzindoos a mudanças nas atitudes frente à experiência que propicia outra forma de se pensar o processo da apropriação do conhecimento.

As propostas de Freinet se encaixam na escola indígena ao se perceber que ambas consideram que o trabalho na escola não é só didático, mas também prática ligada ao contexto histórico-social dos alunos, pautada na cooperação e na atividade, em que o discente é sujeito das suas aprendizagens e o professor é mediador, renovando-se a cada dia, em um movimento pedagógico por meio da troca das experiências.

A proposição pedagógica de Freinet (1998, p. 354-355) divide-se em três momentos que se complementam: experimentação - observa, compara, supõe; criação - parte do real, dos conhecimentos formais ou gerados pela experimentação, imaginação para descobrir a utilidade de determinado conhecimento; e documentação - completa, apoia e reforça a informação desejada em diferentes fontes. Estrutura-se em um conjunto de técnicas indissociáveis por meio de organização cooperativa na sala de aula, espaço de diálogo, de conhecimento, na qual se pode realizar roda da conversa para valorização da oralidade e a aula-passeio, dentre outras técnicas, que permitem a utilização dos diferentes tipos de linguagens: desenho, música, escrita alfabética, pintura, dança, para que os discentes expressem seus conhecimentos e troquem informações não só com os alunos, mas também com a comunidade. Essas técnicas contribuem para a apropriação da linguagem oral e escrita ao elaborarem e socializarem os relatos sobre os conhecimentos trabalhados. Quando se realiza a atividade na escola indígena a partir de um tema gerador, está sendo realizada coletânea de materiais elaborados pelos discentes e demais membros da aldeia, logo organizando o máximo de informações possíveis sobre o tema pesquisado.

No processo de realização da pesquisa, orienta-se à realização de aula-passeio - saídas ao ar livre que oportunizam maior contato com o próprio meio -, para ampliar o conhecimento sobre a aldeia. Dessa maneira, a Pedagogia Freinet, filosoficamente, considera o conhecimento do povo e possibilita que o aluno e o professor sejam agentes no processo de ensino e aprendizagem na escola indígena. As técnicas de Freinet contribuem para a presença dos conhecimentos indígenas na escola, porque partem de situações do cotidiano em direção a um processo de ensino e de aprendizagem que promove a apropriação da cultura, construída ao longo da história, possibilitando, ainda, um trabalho promotor de aprendizagem, por meio de situações reais de leitura, de escrita, de pesquisa, de atividades de expressão, das interações sociais, reafirmando que "[...] não deve haver separação entre as aprendizagens do meio escolar e da realidade" (ELIAS, 1997, p. 74).

As experiências com as técnicas de Freinet na formação de professores indígenas cooperam para que o processo escolar possa desenvolver meios para que o direito à apropriação da cultura, aos bens culturais historicamente construídos pelo homem, ao longo da história, seja observado na prática docente, além de possibilitar acesso e apropriação de conhecimentos sobre seu respectivo povo e de outros. Por sua vez, o registro proposto por Freinet é alternativa para reflexão e 
reestruturação das práticas pedagógicas, tornando-se peças de um processo de formação do educador diante do seu próprio trabalho. Ressalta-se que, quanto mais a produção demonstrar a identidade do povo, maior será o desejo em partilhar com os outros, de mostrar o que fez, de apresentar suas experiências.

Às técnicas de Freinet no processo de formação de professores indígenas na Área Letras e Artes são acrescidas as sequências didáticas de ensino de línguas, considerando que o processo de escrita desenvolvido nas atividades propostas por Freinet reafirmam que não cabe mais o ensino de língua sem a teoria dos gêneros discursivos, que ganham corpo em textos escritos e orais, aos quais falantes, leitores e escritores empregam recursos linguísticos e textuais em situações de uso da língua.

A partir dos gêneros ou por meio deles são estabelecidos eixos que direcionam o ensino da língua materna: "oralidade, leitura, produção de texto escrito e análise linguística" (BRASIL, 1997, p. 40). Segundo Schneuwly \& Dolz (2004, p. 144) "os gêneros constituem um ponto de referência concreto para os alunos", implicando na utilização de uma metodologia centrada em atividades interligadas e planejadas que possibilitem a apropriação gradual de um gênero, isto é, por meio de sequências didáticas, que permitem integrar as práticas sociais de linguagem - escrita, leitura e oralidade -, guiando as intervenções do professor.

A estrutura básica de uma sequência didática segue a apresentação da situação - visa compartilhar com o aluno a proposta de trabalho a ser desenvolvida; elaboração de uma primeira produção oral ou escrita - o professor verificará o conhecimento prévio do aluno a respeito do estudo proposto e quais atividades deverão ser elaboradas; módulos - atividades a serem desenvolvidas de modo organizado e sistematizado para que o aluno se aproprie do gênero; e produção final - os alunos demonstrarão os conhecimentos adquiridos e o professor avaliará as atividades.

Para Barros-Mendes, Cunha \& Teles (2012, p. 22), dessa estrutura desprendem-se três modalidades de atividades que possibilitam ações didáticas que culminam na aprendizagem significativa: atividades exploratórias - possibilitam novas aprendizagens através do levantamento dos conhecimentos prévios; sistematização - aprofundamento dos conhecimentos a serem adquiridos; e avaliativas - mobilização de vários saberes construídos em diferentes atividades no decorrer e no final da sequência didática.

Os referidos autores (2012, p. 21) acrescentam que, na sequência didática, o professor poderá incluir várias atividades: "leitura, pesquisa individual ou coletiva, aula dialogada, produções textuais, aulas práticas", pois a sequência "visa trabalhar um conteúdo, um tema ou um gênero textual da exploração inicial até a formação de um conceito, uma elaboração prática, uma produção escrita", conforme se propõe nas atividades de formação de professores indígenas.

Soma-se a essas atividades o estudo gramatical contextualizado, objetivando auxiliar na compreensão do estudo. $O$ trabalho com a gramática é de análise e reflexão sobre os usos da língua oral e escrita, para que os alunos reflitam sobre a fala e percebam sua organização na propagação dos discursos, considerando que os alunos já chegam à escola falando, mas “o desempenho de práticas orais formais pode ser desenvolvido na escola, via apresentação de seminário, realização de debates, entrevistas" (CAVALCANTE; MELO, 2003. p. 181). 
As sequências didáticas promovem a integração de saberes, proporcionando uma aprendizagem significativa e contextualizada, aproximando os alunos de situações reais de usos da língua. As sequências conseguem sistematizar conteúdos e temáticas estabelecidas no currículo escolar, e como proposta sequenciada, um conhecimento dependerá do outro e se articulará em torno do produto final, oferecendo oportunidades constantes de mediação e intervenção por parte do professor.

Finalmente, na perspectiva de promover a interculturalidade na escola, propõe-se a realização de atividades voltadas à Transposição Didática, quando "um conteúdo de saber" foi apreendido pelo professor em formação passa a ser adequado ao contexto escolar, formando "um conjunto de transformações adaptativas que irão torná-lo apto a ocupar um lugar entre os objetos de ensino", isto é, "um objeto de saber a ensinar" passa a ser "um objeto de ensino" (CHEVALLARD, 1991, p.39), contribuindo dessa forma para a elaboração de proposta de material didático diferenciado.

Para além das discussões teóricas das disciplinas, os professores indígenas em formação, dentro desse movimento metodológico, demandam ampliação de análise centrada na ressignificação dos conhecimentos teóricos para a prática docente, considerando que a docência indígena ainda vem sendo pautada na reprodução de atividades outrora desenvolvida para/entre eles, utilizando materiais didáticos que não contribuem para o fortalecimento da cultura e da identidade indígena.

Nesse processo, os textos e conhecimentos construídos - tanto oral quanto escrito, tanto em língua indígena, quanto em língua portuguesa - abrem espaços às diferentes vozes que emergem não só dos conhecimentos apreendidos na Universidade, mas também dos conhecimentos acumulados pelos povos indígenas, representantes de realidades socio-históricas distintas, que devem ser consideradas, inclusive na prática docente do professor indígena, promovendo o processo intercultural, entendido como uma das principais características da educação escolar indígena, por contribuir para o cumprimento dos demais princípios da educação escolar indígena.

Diniz e Santos (2019, p. 70) destacam que o processo da interculturalidade possui "base no relativismo cultural e na alteridade, quando busca uma inter-relação horizontalizada entre culturas", ou seja consiste em "tratativa do pluralismo cultural não só no âmbito teórico, mas também nas experiências e atividades de inter-relação entre sujeitos de culturas diversas, possibilitando processos de problematização e reflexão acerca de preconceitos, estereótipos e etnocentrismo".

A interculturalidade tanto no contexto acadêmico quanto na escola da aldeia é um dos caminhos para reforçar tanto o fortalecimento da língua, quando se utiliza o direito ao uso das línguas indígenas, quanto o combate à discriminação, preconceitos e exclusão que os povos indígenas vêm sendo vítimas, mesmo após terem reconhecidos nas reformas políticas e educacionais, a partir da Constituição Federal de 1988, o direito a processos próprios de aprendizagem, que demandam currículos escolares que se aproximem da realidade cultural dos alunos, oportunizando um aprendizado significativo, crítico e situado sociohistoricamente. 


\section{Considerações}

O curso de Licenciatura Formação de Professores Indígenas/FACED/UFAM corrobora para o entendimento de que novas e diferentes iniciativas de acesso indígena à formação específica poderão contribuir para a construção de relações sociais interculturais, constituindo-se como importantes espaços que contribuem para fortalecimento dos projetos educativos das comunidades indígenas.

Para tanto, a área Letras e Artes do curso tem se valido da Pedagogia de Projetos, visando promover a ressignificação do processo educativo de maneira a torná-lo objetivo e operacional, possibilitando aos professores indígenas participarem no reajustamento da escola indígena, valorizando o conhecimento e a participação dos alunos.

Paralelamente à Pedagogia de Projetos, as técnicas de Freinet, a sequência didática de ensino de língua e a transposição didática permitem que a formação e a escola indígena trabalhem com os conhecimentos tradicionais dos povos indígenas, vinculados ao conteúdo do currículo escolar, favorecendo melhor compreensão do contexto do social, educacional, político e econômico.

No entanto, essas metodologias ainda não se tornaram procedimentos metodológicos constantes no espaço escolar, talvez pelas condições de muitas escolas, mas principalmente, pelas lacunas na formação de muitos professores, pois desenvolver uma atividade que envolva esses conhecimentos demanda um olhar interdisciplinar para os conteúdos e habilidades diversas, bem como para realizar a transposição didática.

Diante dessa demanda, reafirma-se a preocupação em formar professores para o trabalho pedagógico diferenciado e significativo, enfocando a necessidade de procedimentos metodológicos, como pedagogia de projetos, de Freinet, sequências didáticas, transposição didática, no desenvolvimento de práticas de leitura e escrita, assim como no cumprimento dos princípios da educação escolar indígena no processo educacional e a elaboração de materiais didáticos específicos.

Reafirma-se que o trabalho desenvolvido na formação de professores indígenas e na escola dependerá da intencionalidade docente, do que e de como se propõe. Se o desejo é que os alunos se apropriem da cultura e fortaleçam a identidade étnica, precisa-se reorganizar a formação e a escola de maneira que atenda às especificidades dos povos indígenas. Destaca-se que os cursos de Licenciaturas Interculturais são relativamente jovens, logo, todas as ações ainda estão em processo de reflexão para acertar com as futuras turmas para formação de Professores Indígenas.

\section{Referências}

BARROS-MENDES, A.; CUNHA, D. A.; TELES, R. Organização do trabalho e sequências didáticas. PNAIC: alfabetização em foco. Brasília: MEC, SEB, 2012.

BRASIL. Parâmetros Curriculares Nacionais: língua portuguesa/Secretaria de Educação Fundamental. Brasília: MEC/SEF, 1997.

BRASIL. Resolução CNE/CEB n 05, de 22 junho de 2012. Diário Oficial da União, Poder Executivo, Brasília, 25 jun. 2012. Seção 1, p. 7. Disponível em < http://portal.mec.gov.br/index.php? 
option=com_docman\&view=download\&alias=11074-rceb005-12-pdf\&category_slug=junho-2012pdf\&Itemid=30192>. Acesso em 15 jun. 2019.

BRASIL. Decreto ${ }^{\circ}$ 6.861, de 27 de maio de 2009. Diário Oficial da União, Poder Executivo, Brasília, 28 mai. 2009. Seção 1, p. 23. Disponível em < http://www.planalto.gov.br/ccivil_03/_Ato20072010/2009/Decreto/D6861.htm>. Acesso em 15 jun. 2019.

CAVAlCANTE, M.; Mello, C. Oralidade e Ensino Médio. BUnZEN, C.; MENDONÇA, M. (Orgs.). Português e formação do professor. São Paulo: Parábola, 2003.

DEWEY, J. Democracia e educação: introdução à filosofia da educação. Tradução de Godofredo Rangel e Anísio Teixeira. 4. ed. São Paulo: Nacional, 1979.

DINIZ, A. P.; SANTOS, J. N. A interculturalidade nas práticas pedagógicas do estágio dos alunos da turma Mura do curso de licenciatura em Formação de Professores Indígenas/FACED/UFAM. SOUSA, A. T. S., BACURY, G. R.; GARCIA, F. M. (Org.). Os desafios amazônicos: Educação, Currículo e Política. São Paulo: Garcia Edizioni, 2019.

ELIAS, M. D. C. Célestin Freinet. Petrópolis, RJ: Vozes, 1997.

FREINET, C. As técnicas Freinet da Escola Moderna. Lisboa: Estampa, 1973.

FREINET, C. O itinerário de Célestin Freinet. Rio de Janeiro: Francisco Alves, 1979.

FREINET, C. Pedagogia do Bom Senso. Tradução: J. Baptista. Martins Fontes. SP, 1998.

FREINET, C. Nascimento de uma Pedagogia Popular. Lisboa: Estampa, 1969.

HERNANDEZ, F. Transgressão e Mudança na Educação: os projetos de trabalho. Tradução Jussara Haubert Rodrigues. Porto Alegre: Artes Médicas Sul, 1998.

SANTOS, J. N.; SANTOS, R. F. M. Currículo, Didática e Formação Específica para Professores Indígenas. Atas do XI CQC/VII CLBQC. Braga: Portugal, 2014.

SCHNEUWLY, B.; DOLZ, J. Gêneros orais e escritos na escola. Tradução e organização de Roxane Rojo e Glais Sales Cordeiro. 3 ed. Campinas: Mercado de Letras, 2004.

XAVIER, M. E.; RIBEIRO, M. L.; NORONHA, O. M. História da Educação: a escola no Brasil. São Paulo: FTB, 1994.

UFAM. FACED. Projeto Político Pedagógico do Curso de Licenciatura em Formação de Professores Indígenas. Manaus, 2010. 